all seen the new lease of life and restoration to health when all drugs (except those in categories $a$ and $b$ ) are crossed off. Also the fewer the drugs prescribed, the more likely is compliance. How to educate patients about their drugs is becoming even more important. One simple method is for each tablet to be stuck on a card by Selotape with its name and purpose beside it: for example, allopurinol-to prevent attacks of gout.

It was a step forward in educating the patient when the name of the drug and instructions were written on the label of the bottle, instead of the former sterile secrecy. But, no doubt however hard we try, errors in communication will still occur. One amusing and less serious example happened at my outpatients Queen Elizabeth Hospital, Birmingham.
A middle-aged woman had been prescribed phenylbutazone thrice daily by her family doctor. Her conversation went as follows: 'Marvellous in stopping pain but I can't go on with the tablets . . . no sideeffects ... it's just that doctor told me to take them with a drink ... on the third day I got tired of sherry and changed to gin and tonic but later my husband suggested Scotch'. She was a sensible woman but lived in a circle of society where the invitation 'have a drink' automatically meant alcohol. This is true, whereas the story of the man who, after mistakingly swallowing his suppositories, complained that for all the good they did he might just as well have stuffed them up his arse, is, as far as I know, apocryphal.

CLIFFORD HAWKINS

\title{
Correspondence
}

\section{Implications of a sex difference in osteoarthrosis}

Sir,

We have recently been studying results from examination of the left knee joint at necropsies in Liverpool. Osteoarthritic bone exposure at the patello-femoral articulation was found in 17 of 30 women (57\%) aged 70 to 96 years but in only 4 of 27 men $(15 \%)$ in this age range (chi-square with Yates's modification $8.97 ; \mathrm{P}<0.01$ ). We have also observed that women are twice as numerous as men in patients from North Wales seeking surgical treatment for osteoarthrosis of the hip. Our findings are in line with previous evidence for a sex difference in osteoarthrosis. ${ }^{1}$ This might be attributable to sex differences in gait and skeletal morphology. Also the mean surface area of the patellar articular cartilage is smaller in women than in men, ${ }^{2}$ so that in women this tissue may have less 'functional reserve' against the effects of a degenerative process.

However, another possible explanation would be that there is an inherent sex difference in articular cartilage or in some other component of synovial joints. This possibility has implications for cartilage research. It is helpful if data from studies of cartilage and related tissues are presented separately for women and men. Current hypotheses about the pathogenesis of idiopathic osteoarthrosis can then be tested for their ability to explain the sex difference in this disease.

Radin has suggested that the progression of cartilage degeneration to osteoarthrosis may be influenced by the resilience of the subchondral bone. ${ }^{3}$ Following his suggestion, we have recently shown that progressive cartilage degeneration on the patellar surface can be related to topographical variation in patellar subarti- cular calcified tissue density. However, there is no significant sex difference in the subarticular density values at the two sites we studied.

Freeman and Meachim ${ }^{5}$ have reviewed evidence which suggests that degeneration of cartilage may be due to fatigue failure of its collagen fibre network. It is therefore pertinent that there appears to be a sex difference in the fatigue properties of this material. ${ }^{6}$ It would be of interest to know if there are any sex differences in the other mechanical properties of articular cartilage, its metabolism, its proteoglycan profile, and its enzymatic degradation, or differences in the wear-protective properties of synovial fluid.

\section{G. Meachim, R. Barbara Pedley Department of Pathology, Duncan Building, Royal Liverpool Hospital, Liverpool.}

\section{References}

1 Kellgren J H. Osteoarthrosis in patients and populations. Br Med J 1961; 2: 1-6.

2 Meachim G, Emery I H. Quantitative aspects of patellofemoral cartilage fibrillation in Liverpool necropsies. Ann Rheum Dis 1974; 33: 39-47.

3 Townsend P R, Rose R M, Radin E L, Raux P. The Biomechanics of the human patella and its implications for chondromalacia. $J$ Biomechanics 1977 ; 10; 403-7.

- Pedley R Barbara, Meachim G. Topographical variation in patellar subarticular calcified tissue density. $J$ Anat 1979; 128: 737-45.

5 Freeman M A R, Meachim G. Ageing and degeneration. In: Freeman M A R, ed. Adult Articular Cartilage, 2nd ed. London: Pitman, 1979; 487-543.

- Kempson G E. Mechanical properties of articular cartilage. In: Freeman M A R, ed. Adult Articular Cartilage, 2nd ed. London: Pitman, 1979; 333-414. 